\section{Acute Abdomen in Rheumatoid Arthritis due to Necrotizing Arteritis}

\author{
M. K. LINDSAY, H. B. TAVADIA, A. S. WHYTE, \\ P. LEE, J. WEBB
}

British Medical fournal, 1973, 2, 592-593

Though the major features of rheumatoid arthritis are related to the joint morbidity a wide variety of systemic manifestations may occur at any time as specific complications of "malignant" rheumatoid disease (Hart, 1966). The most serious of these complications are due to necrotizing arteritis. That such arteritis may be the cause of serious medical and surgical complications occurring in patients with rheumatoid arthritis is still generally not appreciated. The present report concerns such a patient who developed intestinal infarction consequent on necrotizing arteritis and discusses the abdominal complications which may occur in such patients.

\section{Case Report}

A married woman aged 56 developed seropositive (Rose-Waaler titre 1/128) erosive nodular rheumatoid polyarthritis 10 years previously, which was continuously active from the time of onset and little affected by salicylates, the only therapy given. In 1969 she developed bilateral pitting rheumatoid oedema of the lower limbs and Felty's syndrome (950 polymorphs out of 2,500 leucocytes $/ \mathrm{mm}^{2}$, with mild splenomegaly).

An episode of pleurisy in March 1971 was followed by increased activity of polyarthritis, general malaise, progressive weight loss, and recurrent minor skin and oropharyngeal infections. Crops of digital vasculitis lesions round nailfolds and small, painful haemorrhagic maculo-papular skin lesions on the trunk occurred from October 1971. In February 1972 the patient developed a painful and extensive skin eruption on the trunk and proximal limbs, composed of sharply demarcated irregular haemorrhagic areas ranging up to $8 \mathrm{~cm}$ diameter, with coalescence in some places and haemorrhagic bullae up to $2 \mathrm{~cm}$ in other areas (fig. 1). A minor rectal haemorrhage occurred one week later and she was admitted to hospital the following week.

The patient appeared chronically ill and wasted, with extensive rheumatoid joint deformities and numerous subcutaneous nodules. Besides the skin and nailfold lesions there was pitting oedema of both lower limbs and moderate hepatosplenomegaly. The temperature, blood pressure, and urine were normal. The skin lesions were considered due to necrotizing arteritis complicating the rheumatoid disease.

Four days after admission an episode of colicky central abdominal pain with the passage of a small melaena was followed several hours later by increasingly severe and continuous abdominal pain and vomiting. She became febrile, $39^{\circ} \mathrm{C}$, with a silent distended abdomen, and developed shock. Intensive resuscitative measures were instituted, including intravenous fluids, antibiotics, and large doses of hydrocortisone. There appeared to be clinical improvement for several days though abdominal distension persisted. Fever then recurred and chest radiography showed basal consolidation and subdiaphragmatic gas. Laparotomy was then performed. There was generalized peritonitis and multiple small areas of necrosis in the caecal wall. Partial colectomy without anastomosis, with ileostomy and colostomy, was performed. Some 12 hours after the operation fresh bleeding from the ileostomy site was followed by shock, and the patient died.

Royal Infirmary, Glasgow G4 OEH

M. K. LINDSAY, M.B., B.Sc., Senior House Officer

H. B. TAVADIA, M.B., D.R.C.O.G., Assistant Pathologist

Southern General Hospital, Glasgow S.W.1

A. S. WHYTE, M.B., ch.B., Registrar in Surgery

Centre for Rheumatic Diseases, Glasgow C.4

P. LEE, M.B., M.R.A.C.P., Senior Registrar

J. WEBB, M.B., M.R.A.C.P., Lecturer in Medicine

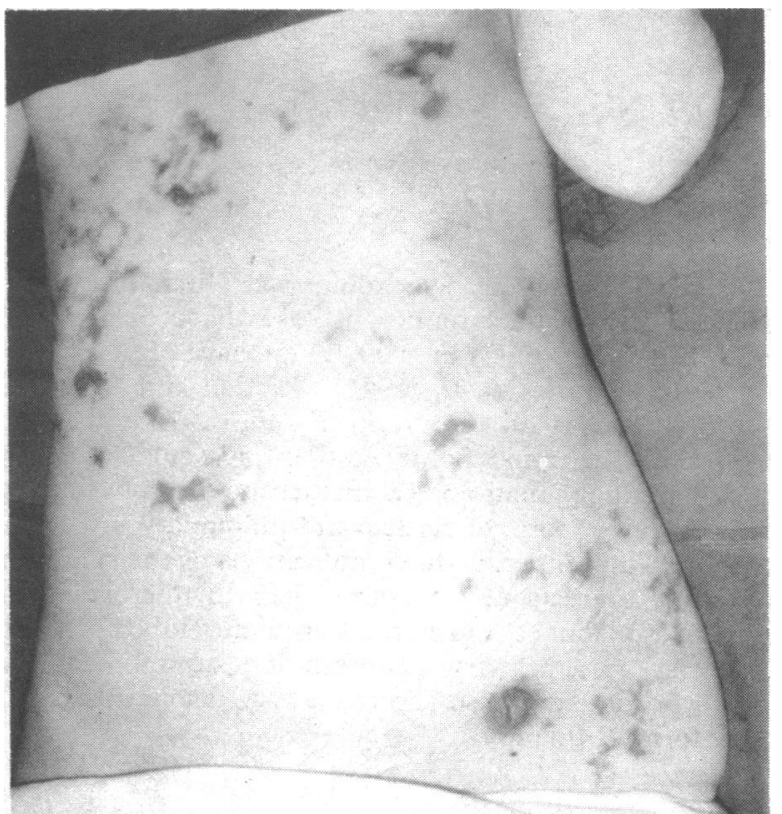

FIG. 1-Photograph on admission showing haemorrhagic macular and bullous lesions on trunk.

\section{NECROPSY FINDNGS}

Postmortem examination showed the presence of typical rheumatoid joint deformities, subcutaneous nodules, and several circumscribed areas of haemorrhagic skin necrosis on the abdomen and thighs. There was moderate intraperitoneal haemorrhage from the ileostomy site in addition to generalized fibrinous peritonitis. The resected colon was congested, friable, and thickened from fibrinous adhesions, with two paper-thin areas of infarction. The liver was pale and enlarged to $2,100 \mathrm{~g}$, the spleen weighed $300 \mathrm{~g}$, and the lungs showed bilateral basal consolidation and pleuritis. Other findings were normal.

Histological findings of interest were confined to the intestinal walls and mesentery and the skin. The caecum was ulcerated and infarcted, the submucosal vessels showing acute inflammatory and necrotizing arteritis with fibrinoid necrosis (fig. 2), with similar changes affecting larger arteries of the mesenteric arcades (fig. 3). In other areas submucosal arteries showed evidence of occlusion with recanalization (fig. 4), indicating previous arteritis with thrombosis. Margins of skin lesions showed an identical necrotizing arteritis. No evidence of

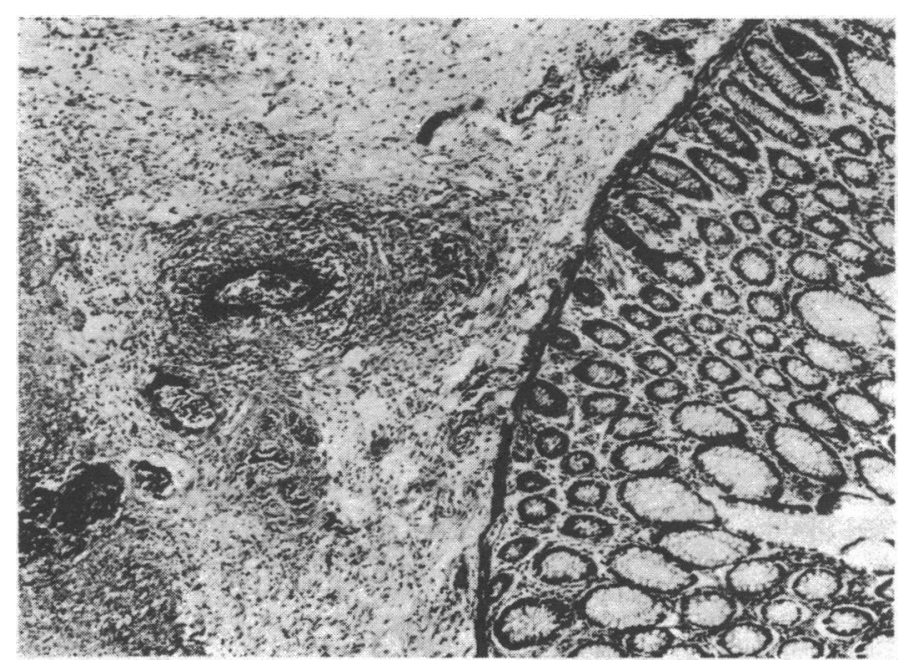

FIG. 2-Photomicrograph of caecal wall showing intact mucosa with inflammatory necrotizing arteritis of submucosal artery. (M.S.B. $\times 54$.) 


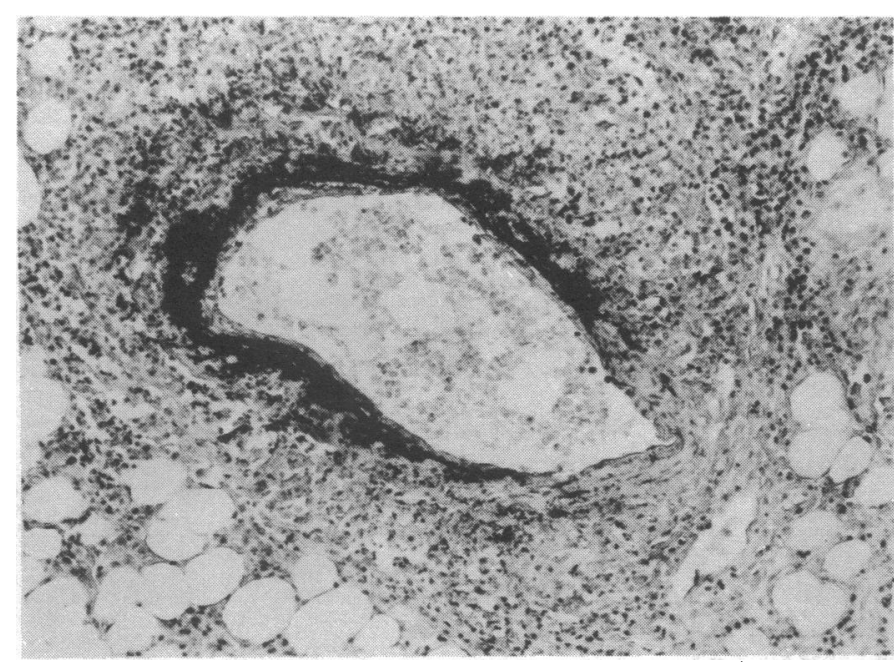

FIG. 3-Photomicrograph of small mesenteric artery showing fibrinoid necrosis of part of vessel wall. (M.S.B. $\times 134$.)

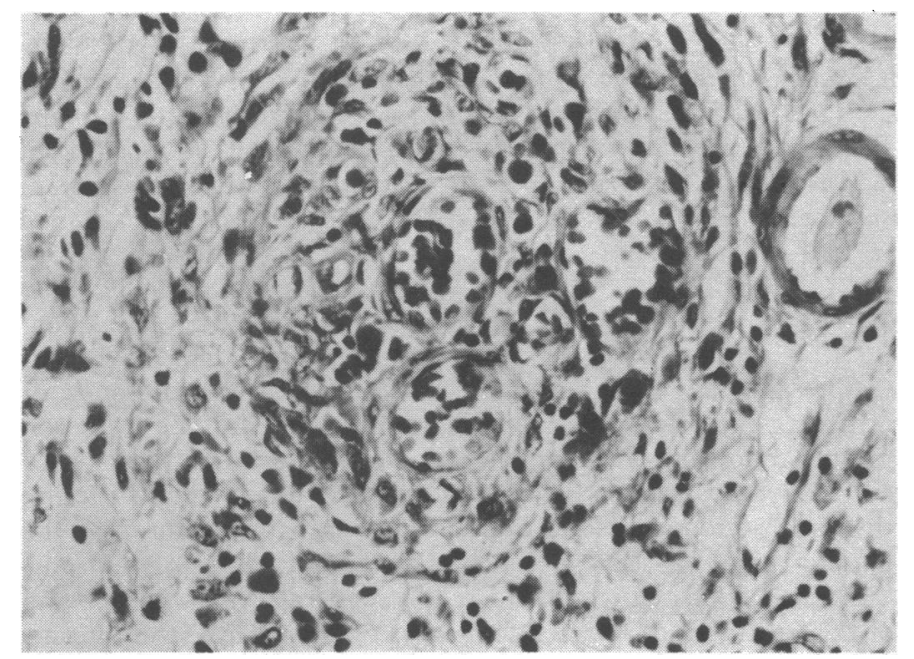

FIG. 4-Photomicrograph of submucosal artery, which shows evidence of recanalization. $(\mathrm{H}$. and $\mathrm{E} . \quad \times 134$.

arteritis elsewhere was found. The liver showed periportal fatty change, with a moderate lymphocytic infiltration of portal tracts. There was a severe confluent bronchopneumonia.

\section{Comment}

Rheumatoid arthritis is a common disease, the systemic nature of which tends to be overlooked at times. Nevertheless, the typical subcutaneous nodules are now well known to occur in diverse sites, perhaps the pleura, lungs, pericardium, and myocardium being the best known. Their basic pathology has been shown to be an inflammatory vasculitis (Sokoloff, 1963). Inflammatory arteritis per se may complicate rheumatoid arthritis at any time, usually affecting patients with severe arthritis, subcutaneous nodules, and high titres of rheumatoid factor (Bywaters and Scott, 1963). This necrotizing arteritis is indistinguishable histologically from polyarteritis nodosa and may similarly cause a wide variety of clinical manifestations having a grave prognosis (Hart, 1966), differing from the latter, however, in that peripheral sensorimotor neuropathy is the most frequent manifestation in rheumatoid arthritics (Pallis and Scott, 1965).

When the rheumatoid patient develops abdominal pain and no clear-cut diagnosis of the more common acute abdominal conditions appears likely, several complications due to arteritis require consideration. The most common is multiple ischaemic ulcers of the intestine, which usually cause severe haemorrhage and may perforate. Involvement of larger arteries may cause segmental or extensive bowel gangrene or intraperitoneal haemorrhage (West and Newns, 1953; Parker and Thomas, 1959; Adler et al., 1962; Webb and Payne, 1970). Perisplenitis and splenic infarcts are well known to cause left hypochrondrial pain in rheumatoid patients (Sinclair and Cruickshank, 1956), and acute arteritis of hepatic, cystic, pancreatic, and renal vessels, and of the peritoneum itself, has been recorded. Perforation of peptic ulcer and renal papillary necrosis are complications of drug therapy for rheumatoid arthritis causing acute abdominal pain.

Diagnosis of arteritis as the cause of an acute abdomen in rheumatoid patients depends on awareness of its occurrence. Subsequent management should be based on surgical necessity, though early laparotomy following resuscitation may be lifesaving (Parker and Thomas, 1959). Though there is no definitive therapy, encouraging remissions have been reported when surgery was followed by anticoagulants or low molecular weight dextran and steroids, by penicillamine, and by immunosuppressives. Steroids are no longer thought to play more than a contributory part in the development of such arteritis (Schmid et al., 1961), and their administration in high dosage appears to offer the best chance to obtain suppression and perhaps remission of this grave complication occurring acutely.

We thank Mr. C. J. Longland and Professor W. W. Buchanan for permission to report this case.

\section{References}

Adler, R. H., Norcross, B. M., and Lockie, M. (1962). Fournal of the Bywaters, E. G. L., and Scott, J. T. (1963). Fournal of Chronic Diseases, 16,
905.

Hart, F. D. (1966). British Medical fournal, 2, 131.

Pallis, C. A., and Scott, J. T. (1965). British Medical fournal, 1, 1141.

Parker, R. A., and Thomas, P. M. (1959). British Medical fournal, 1, 540. Schmid, R. F., Cooper, N. S., Ziff, M., and McEwan, C. (1961). American fournal of Medicine, 30, 56.

Sinclair, R. J. G., and Cruickshank, B. (1956). Quarterly fournal of Medicine,

25, 313.
Sokoloff, L. (1963). In The Peripheral Blood Vessels, ed. J. L. Orbison and D. E. Smith. Baltimore, Williams and Wilkins.

Webb, J., and Payne, W. H. (1970). Australasian Annals of Medicine, 19, 168. West, H. F., and Newns, G. R. (1953). Lancet, 2, 1123. 